\title{
Mein Land
}

Mein Land ist phasenweise unbewohnt

kennt derzeit kaum die Gegenwart, weiss von der Vergangenheit

und scheut die Zukunft wie ein rotes Tuch.

Mein Land ist meine kleine, ganz persönliche Welt,

die Besuchern manchmal herzlich die Türe öffnet, sich wiederum

ein andermal wie eine Muschel verschliesst.

Die Land-Schaft, die mich umgibt, ist steinig und karg um

alsbald farbig und voller flimmernder Muster zu sein -

sie lockt mich immer wieder auf eine Reise ins Ungewisse,

ausgerüstet mit schwerem Koffer und reichlich Proviant - denn, wer weiss,

was mich in diesem Land noch alles erwartet?

Die Grenzen meines Landes sind beklemmend eng und gleichzeitig

fast unerträglich weit. Die Enge drückt mir den Atem ab und die Weite lässt mich vor Schrecken nach Luft japsen.

Mein Land ist ein Land voller Widersprüche, ein Land voller ungeklärter Rätsel und Überraschungen, bedrohend und spannend zugleich.

Ein Land mit wechselndem Namen, ein Cocktail der Gefühle, ein Mix, der berauscht und besser in kleinen, vorsichtigen Zügen getrunken wird.

Gut dosiert aber, ist mein Land ein Wunder-Land.

Will es jemand bereisen?

Charlotte H. Hurni, Zürich

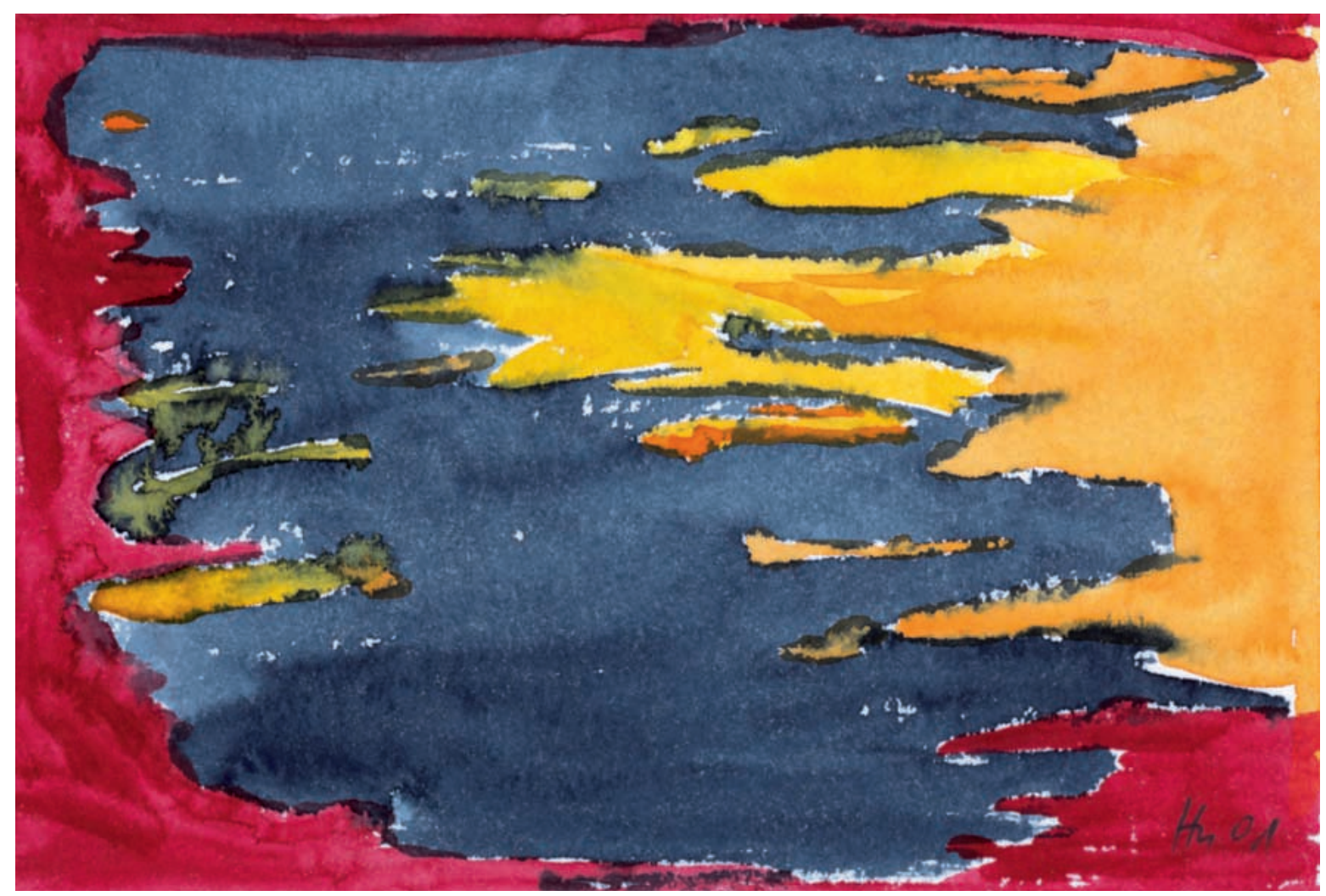

